\title{
Development of a Simple Dielectric Analysis Module for Online Cure Monitoring of a Commercial Epoxy Resin Formulation
}

\author{
Olívia de Andrade Raponi *, Rafael de Andrade Raponi ${ }^{b}$, Gabriel Bissaro Barban ${ }^{a}$, Ricardo Mello Di \\ Benedetto $^{a}$, Antonio Carlos Ancelotti Junior ${ }^{a}$ \\ ${ }^{a}$ Mechanical Engineering Institute, Universidade Federal de Itajubá - UNIFEI, Av. BPS, 1303, Itajubá,
MG, Brazil \\ ${ }^{b}$ Information Technology and System Engineering Institute, Universidade Federal de Itajubá - UNIFEI, \\ Av. BPS, 1303, Itajubá, $M G$, Brazil
}

Received: January 17, 2016; Revised: June 23, 2017; Accepted: July 03, 2017

The final properties of thermosets are strongly dependent on their curing process. Therefore, closely monitoring this process is necessary to assure the manufacturing quality and productivity. In this way, the aim of this study is to develop a simple dielectric module for monitoring and optimizing the industrial curing cycle of thermosets. The module is based on a data acquisition system and an interdigital sensor that remains in contact with the resin throughout the entire curing process. Dielectric analysis (DEA) was performed in a commercial epoxy resin formulation widely used as a matrix for thermoset composites, which was submitted to a pre-established and validated curing cycle. The properties derived from DEA measurements are in accordance with differential scanning calorimetry (DSC) results, allowing the identification of key stages of the curing process. The similarity between the results of both techniques is a strong indicative of the possibility of using the developed module as an alternative for industrial cure monitoring and optimization.

Keywords: online cure monitoring, dielectric analysis, epoxy resin, thermosets

\section{Introduction}

Monitoring the curing process of thermosets can assure better final properties and reduce the processing time of these materials ${ }^{1}$. There are many methods of cure monitoring, however, mostly only applicable in laboratories and non-adaptive to industry application. Therefore, this monitoring is usually limited to time and temperature control based on the resin's supplier recommendations. Nevertheless, using advanced techniques for curing process control may bring great advantages like: adapting the cure cycle according to storage time and chemical integrity of the resin ${ }^{2}$, as well as improving quality and considerable reducing waste, time and energy spent on the process.

New tendencies in the online cure monitoring of thermoset composites have been studied ${ }^{3-6}$. Among several cure-monitoring methods, dielectric analysis (DEA) is known to be a well stablished technique for monitoring cure during a production operation ${ }^{5}$ and the most mature online cure monitoring technology $y^{7}$. This sort of analysis is performed with sinusoidal excitations at specific frequencies that generate a current waveform used to calculate the frequency dependent dielectric properties of the material by applying the Fourier transform ${ }^{5}$.

In order to perform the measurements in dielectric analysis, a small sensor can be placed in contact with the resin. A voltage is applied to the element by an electronic impedance analyzer that is connected to the sensor and measures impedance ${ }^{2}$. The sensor response is affected by the resin polar side groups ${ }^{2}$, whose mobility decreases as the cure reaction advances. Therefore, the impedance of the sensor and resin combination changes proving its relationship with the resin viscosity ${ }^{7}$.

The purpose of this study is to develop a simple measurement module for dielectric analysis that can be applied on industries to monitor the curing process of a commercial epoxy resin, widely used as a matrix for advanced thermoset composites. The module is based on a high precision impedance converter system combined with an interdigital sensor and its aim is to provide a high-quality curing control with a low production and application cost.

\section{Materials and Methodology}

\subsection{Materials}

The commercial epoxy system used was: Araldite ${ }^{\circledR}$ LY 5052, a low-viscosity resin with Aradur ${ }^{\mathrm{TM}} 5052$ hardener, which is a mixture of polyamines. This system is usually applied on aerospace and industrial composites, tooling and aircraft repair, especially by its characteristics of low 
viscosity, easy impregnation of reinforcement materials, elevated temperature resistance and excellent mechanical and dynamic properties according to the manufacturer ${ }^{8}$. The resin and hardener system will be from now on referred as epoxy.

\section{$2.2 \mathrm{DSC}$}

The initial characterization of the epoxy curing process was performed using DSC analyses. A preliminary dynamic run was carried out by placing an epoxy sample of $1.45 \mathrm{mg}$ in an aluminium hermetic pan. The sample was then heated from $25-250^{\circ} \mathrm{C}$ with a $5^{\circ} \mathrm{C} / \mathrm{min}$ heating rate, in a nitrogen atmosphere with 50 $\mathrm{ml} / \mathrm{min}$ flow rate using a DSC Q20 2151 TA Instruments equipment. The results of this run were applied to estimate the kinetic parameters and forecast the curing degree in isothermal cycles by the kinetic method of Borchardt and Daniels.

This method selection was made based on the methodology presented by Costa et al. ${ }^{9}$ and the kinetic parameters of activation energy $\left(E_{a}\right)$, pre-exponential factor $(A)$ and reaction order $(n)$ were calculated as described by ASTM E2041 ${ }^{10}$. After the calculation of these parameters, the curing degree $(\alpha)$ forecast was made by Equation $1^{11}$, in which $t$ and $T$ are the time and temperature for the isothermal curing cycle and $R$ is the gas constant $(8.314 \mathrm{~J} / \mathrm{mol} . \mathrm{K})$ :

$$
\alpha=1-\left[1-(1-n) \cdot A \cdot t \cdot e^{\left.\left(\frac{-E a}{R T}\right)\right]^{\left(\frac{1}{(1-n)}\right)}}\right.
$$

A well-established isothermal industrial curing cycle was analyzed by both curing degree forecast and isothermal DSC run. The latter was performed by placing an epoxy resin sample of $1.50 \mathrm{mg}$ in an aluminium hermetic pan and carrying out its cure inside the DSC furnace at $80^{\circ} \mathrm{C}$ during 240 minutes. To verify the efficiency of the chosen curing cycle, the same sample was subjected to a second dynamic run from 25 to $300^{\circ} \mathrm{C}$, with a heating rate of $10^{\circ} \mathrm{C} / \mathrm{min}$ to evaluate the presence of residual reaction peaks that would indicate an incomplete curing reaction from the isothermal cycle. Both analyses were also carried in a nitrogen atmosphere, with a $50 \mathrm{ml} / \mathrm{min}$ flow rate, using the same DSC equipment.

From the isothermal DSC data, it was also possible to calculate the degree of cure $(\alpha)$ as a function of time based on Equation 2, where $H(t)$ is the heat of reaction at the instant $t$, and $H_{T}$ represents the total heat of the reaction ${ }^{12}$, both obtained by partial and total peak integrations of the DSC curve.

$$
\alpha(t)=\frac{H(t)}{H_{T}}
$$

\section{$2.3 \mathrm{DEA}$}

For the dielectric analysis, a high precision impedance converter from Analog Devices was used. It combines an on-board frequency generator with 12-bit, 1 MSPS, analog-to-digital converter (ADC). The frequency generator allows an external complex impedance to be excited with a known frequency. The response signal from the impedance is sampled by the on-board ADC and a discrete Fourier transform (DFT) is processed by an on-board DSP engine. The DFT algorithm returns a real (R) and an imaginary (I) data-word at each output frequency, which allows the user to calculate both real $\left(Z^{\prime}\right)$ and imaginary ( $\left.Z^{\prime \prime}\right)$ components of the complex impedance.

The sample measurement behavior is equivalent to the circuit shown in Figure 1, where the complex impedance $(Z)$ is described by the Equation 3 and can be calculated in terms of $R$ and $C$, using Equation 4, where $\omega=2 \pi f$ (angular frequency) and $f$ is the frequency in $\mathrm{Hz}$.

$$
\begin{gathered}
Z=Z^{\prime}-j \cdot Z^{\prime \prime} \\
Z=\frac{R}{1+\omega^{2} R^{2} C^{2}}-j \cdot \frac{\omega R^{2} C}{1+\omega^{2} R^{2} C^{2}}
\end{gathered}
$$

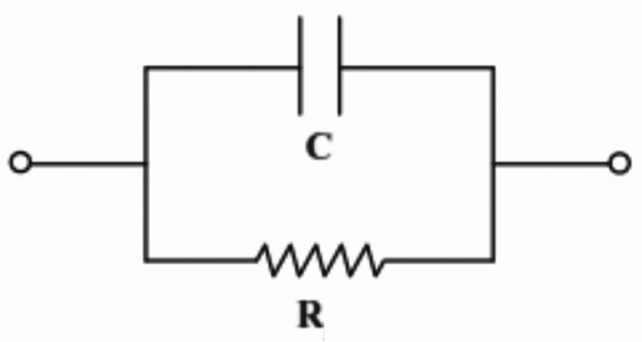

Figure 1. Equivalent circuit for sample measurements DEA.

The real $\left(\varepsilon^{\prime}\right)$ and imaginary ( $\left.\varepsilon^{\prime \prime}\right)$ components of the complex permittivity $\left(\varepsilon^{*}\right)$ are related with the imaginary and real components of the impedance as follows, where, $C_{0}$ is the capacitance of the sensor on air. The real part of the permittivity is also named as the dielectric constant of the material, while the imaginary part represents its loss factor. Both properties can be calculated by Equations 5 and 6 .

$$
\begin{aligned}
& \varepsilon^{\prime}=\frac{Z^{\prime \prime}}{\omega C_{0} Z^{2}} \\
& \varepsilon^{\prime \prime}=\frac{Z^{\prime}}{\omega C_{0} Z^{2}}
\end{aligned}
$$

The mathematical relationship between the imaginary permittivity and the electrical conductivity $(\sigma)$ for low frequencies analyses is given by:

$$
\sigma=\omega \varepsilon^{\prime \prime} \varepsilon_{0}
$$


In which, $\varepsilon_{0}$ is the electrical vacuum permittivity $(8.85 \times$ $10^{-12} \mathrm{farad} / \mathrm{m}$ ). Knowing that the resistivity is the inverse of the electrical conductivity, is now possible to calculate the sample resistivity $(\rho)$ values, hereby named as ion viscosity (IV) and defined as ${ }^{13}$ :

$$
I V=\frac{1}{\sigma}=\rho
$$

Interdigital sensors with dimensions as presented in Figure 2 were manufactured in electronic phenolic board, using a Router CNC SHG 1212 EXCITECH machine. The sensors were then attached to the impedance converter using a twisted cable that supports elevated temperatures, while the impedance converter was connected to a computer using an USB entry.

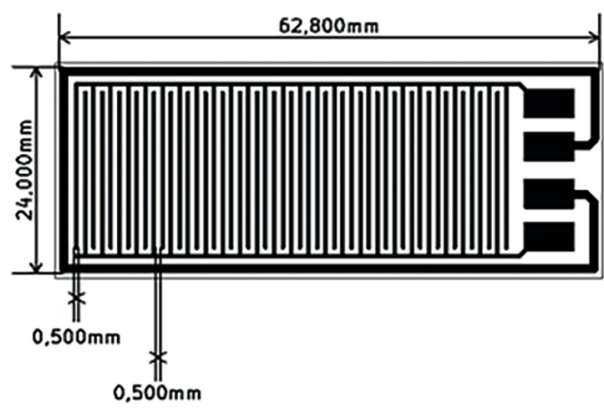

Figure 2. Manufactured interdigital sensor dimensions.

The impedance converter was calibrated with an $1 \mathrm{M} \Omega$ resistor, the interdigital sensor was embedded in epoxy resin and frequency scanning was performed to find the frequency with the best dielectric response. The first scanning covered the frequency range from $1 \mathrm{~Hz}$ to $2 \mathrm{kHz}$, with a $25 \mathrm{~Hz}$ increment for the curing times of $0,60,120$ and 240 min during an $80^{\circ} \mathrm{C}$ isothermal process. Then, to refine the results obtained by this first scanning, a second scanning was performed in the range of 1 to $1.3 \mathrm{kHz}$ with a $0.6 \mathrm{~Hz}$ increment. From the obtained results, the work frequency value was set in $1.1 \mathrm{kHz}$.

Finally, the DEA was performed in the epoxy resin. Its curing took place in an air circulating oven, at $80^{\circ} \mathrm{C}$ and its impedance variation was measured by the dielectric module during $240 \mathrm{~min}$ under the constant frequency of $1.1 \mathrm{kHz}$. Finally, the ion viscosity was calculated and its behavior was compared with the degree of cure obtained by DSC analysis. The assembly for the DEA measurements is schematically presented in Figure 3.

\section{Results and Discussions}

\subsection{DSC}

The results of the dynamic preliminary run, presented in Figure 4, were used to estimate the values presented in

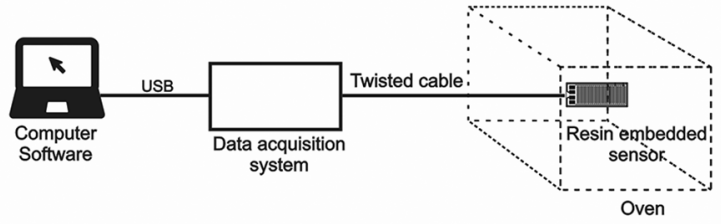

Figure 3. Schematic representation of the assembly for DEA.

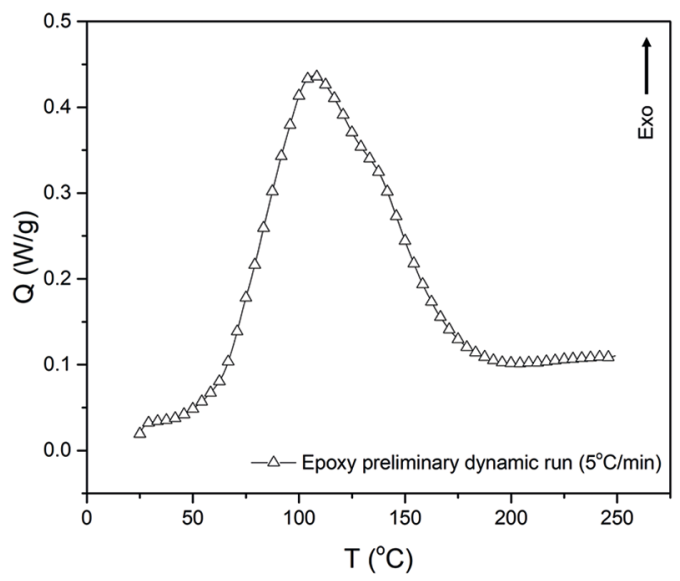

Figure 4. Preliminary dynamic DSC run for the for $1.45 \mathrm{mg}$ sample of Araldite ${ }^{\circledR}$ LY5052/Aradur5052 ${ }^{\mathrm{TM}}$ epoxy system.

Table 1. The total enthalpy $\left(H_{T}\right)$ and the kinetic parameters $\left(E_{a}, \ln A, n\right)$ were calculated by the integration of the reaction peak and Borchardt and Daniels method, respectively, as described before. Also, the onset and endset temperatures were estimated by the tangent method.

It can be noticed that the curing exothermic peak occurs from approximately $57^{\circ} \mathrm{C}\left(T_{\text {onset }}\right)$ to $186^{\circ} \mathrm{C}\left(T_{\text {endset }}\right)$, reaching its maximum value at $106^{\circ} \mathrm{C}\left(T_{\max }\right)$. These temperatures can lead the establishment of appropriate isothermal curing cycles by considering the fact that the isothermal temperature must be between the onset and peak maximum, rather closer to the $T_{\text {onset }}$ in order to assure the properly liberation of volatiles avoiding the presence of porosity in the final part ${ }^{14}$. The total enthalpy, activation energy, pre-exponential factor and reaction order are close to the ones found in literature ${ }^{14,15}$ and were applied in Equation 1 for forecasting the curing degree reached by the epoxy when subjected to different curing temperatures during 240min (Figure 5).

Even though graphic results from Figure 5 can lead to the selection of different isothermal temperatures for 240 min duration curing cycles, the present study focus on the previously mentioned well-established isothermal curing cycle of $80^{\circ} \mathrm{C}$. Therefore, this result is pointed out by the star symbol in the graph, indicating that a curing degree of approximately $100 \%(\alpha \cong 1)$ is reached by these time and temperature parameters.

Figure 6 shows the DSC results for the epoxy resin in: (a) isothermal run at $80^{\circ} \mathrm{C}$ during $240 \mathrm{~min}$ and (b) dynamic 
Table 1. Kinetic parameters obtained from the dynamic DSC preliminary run for the Araldite ${ }^{\circledR}$ LY5052/Aradur5052 ${ }^{\mathrm{TM}}$ epoxy system.

\begin{tabular}{ccccccc}
\hline$T_{\text {onset }}\left({ }^{\circ} \mathrm{C}\right)$ & $T_{\max }\left({ }^{\circ} \mathrm{C}\right)$ & $T_{\text {endset }}\left({ }^{\circ} \mathrm{C}\right)$ & $-H_{T}(\mathrm{~J} / \mathrm{g})$ & $E_{a}(\mathrm{~kJ} / \mathrm{mol})$ & $\ln A\left(\mathrm{~s}^{-1}\right)$ & $\mathrm{n}$ \\
\hline 57 & 106 & 186 & 292 & $(71.56 \pm 0.36)$ & $(20.11 \pm 0.12)$ & $(1.28 \pm 0.01)$ \\
\hline
\end{tabular}

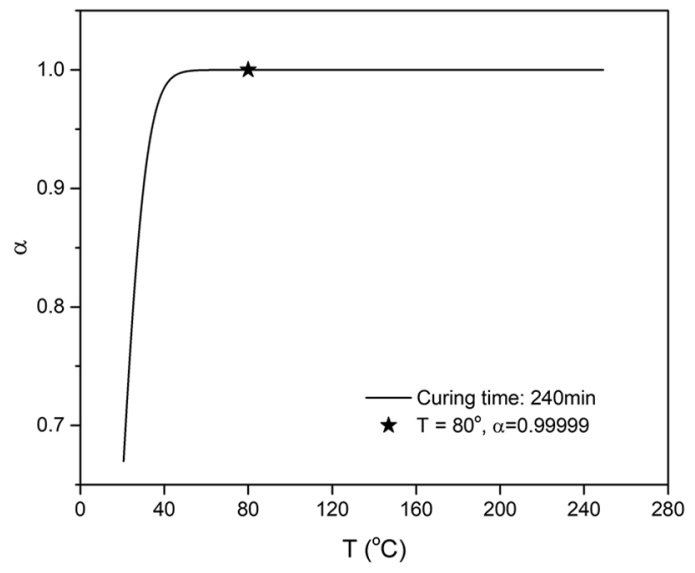

Figure 5. Epoxy system Araldite ${ }^{\circledR}$ LY5052/Aradur5052 $2^{\mathrm{TM}}$ cure degree $(\alpha)$ forecast as a function of temperature (T) for a pre-established time of $240 \mathrm{~min}$.
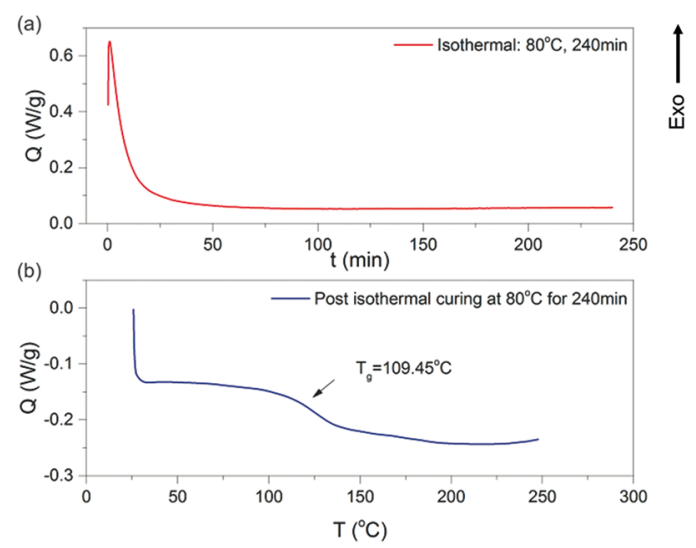

Figure 6. DSC results for the epoxy system Araldite ${ }^{\circledR}$ LY5052/ Aradur $5052^{\mathrm{TM}}$ sample of $1.50 \mathrm{mg}$ : (a) isothermal cure at $80^{\circ} \mathrm{C}$ during $240 \mathrm{~min}$ and (b) second run dynamic for cure verification.

run for cure verification. The combination of these analyses can validate the forecasted isothermal curing parameters and provide data for the calculation of the experimental cure degree as a function of time, for $80^{\circ} \mathrm{C}$, that will work as comparative data for the DEA.

From Figure 6, it can be noticed that the isothermal curing reaction has a n-order behavior, and that there are no residual reaction peaks on the dynamic cycle, which confirms that the time and temperature selected parameters can define an efficient isothermal curing cycle for the epoxy resin being studied.

The dynamic cycle in Figure 6 (b) also presents the glass transition $\left(T_{g}\right)$ temperature of the material, which is $109.45^{\circ} \mathrm{C}$, a value close to the one described in the material's data sheet $\left(103.6^{\circ} \mathrm{C}\right)^{8}$. This temperature reflects the structural behavior of the resin when the cure reaction is complete ${ }^{16}$, therefore, the proximity between the value obtained by DSC analysis and the value presented in the data sheet is also an indicative of an adequate curing cycle.

Another interesting observation is that even though the curing cycle is performed at $80^{\circ} \mathrm{C}$, the material presents a higher value for the $T_{g}\left(109.45^{\circ} \mathrm{C}>80^{\circ} \mathrm{C}\right)$. It is expected that curing cycles performed in temperatures lower than the material's $T_{g}$ cause the system to vitrify during the polymerization ${ }^{17}$. The vitrification process reduces the reaction rate to minimum values, leading to the necessity of a temperature increase to allow the process to continue. However, sub- $T_{g}$ curing cycles can also lead to materials with high $T_{g}$ values, which can be explained by the exothermic character of the curing reaction that supplies the required energy for the continuity of the final chemical structure development process ${ }^{18}$.

\subsection{Frequency scanning for DEA}

The frequency scanning results for the epoxy resin under $80^{\circ} \mathrm{C}$ isothermal curing process are shown in Figure 7. It can be noticed that for 0min the best impedance response occurs around $1.2 \mathrm{kHz}$, while for the other measured times this value becomes closer to $1 \mathrm{kHz}$. The frequency values for the impedance peak for each measured time are summarized in Table 2.

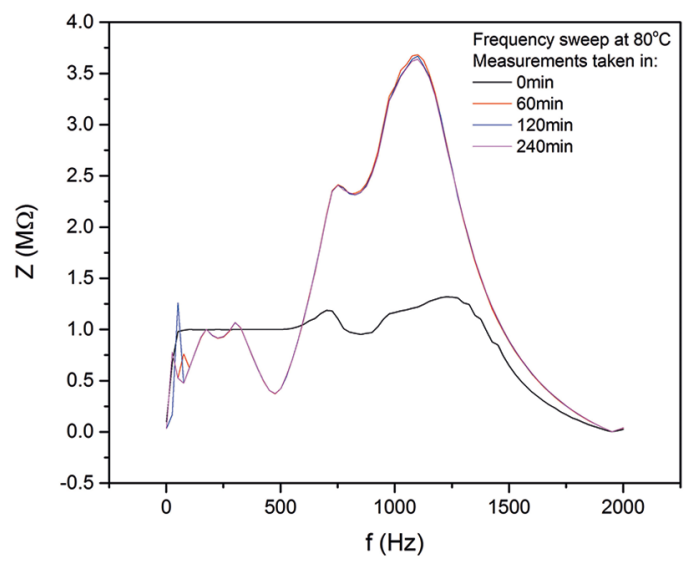

Figure 7. Frequency scanning from $1 \mathrm{~Hz}$ to $2 \mathrm{kHz}$ for the Araldite ${ }^{\circledR}$ LY5052/Aradur5052 $2^{\mathrm{TM}}$ epoxy system under isothermal cure at $80^{\circ} \mathrm{C}$.

Figure 8 shows the results for the second frequency scanning, which evaluates a shorter frequency range $(0.9$ to $1.3 \mathrm{kHz}$ ), with a smaller increment, providing more accurate 
Table 2. Frequency peak values obtained from the $1 \mathrm{~Hz}$ to $2 \mathrm{kHZ}$ frequency scanning.

\begin{tabular}{cc}
\hline Time $(\mathrm{min})$ & Frequency for the impedance peak $(\mathrm{kHz})$ \\
\hline 0 & 1.226 \\
60 & 1.101 \\
120 & 1.101 \\
240 & 1.101 \\
\hline
\end{tabular}

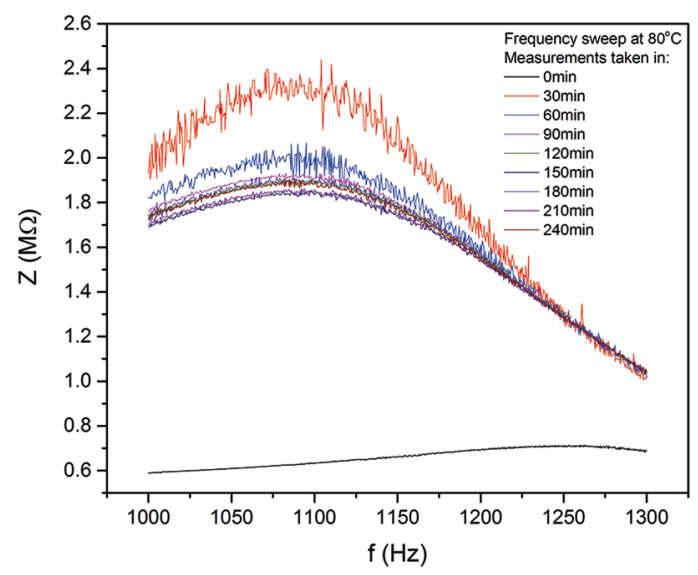

Figure 8. Frequency scanning from 0.9 to $1.3 \mathrm{kHz}$ for the Araldite ${ }^{\circledR}$ LY5052/Aradur $5052^{\mathrm{TM}}$ epoxy system under isothermal cure at $80^{\circ} \mathrm{C}$.

results. It can be noticed that the frequency values for the best impedance response obtained by this second scanning are very close to the ones obtained in the first scanning. These values are summarized in Table 3 .

Table 3. Frequency peak values obtained from the 0.9 to $1.3 \mathrm{kHz}$ frequency scanning.

\begin{tabular}{cc}
\hline Time $(\mathrm{min})$ & Frequency for the impedance peak $(\mathrm{kHz})$ \\
\hline 0 & 1.261 \\
30 & 1.104 \\
60 & 1.095 \\
90 & 1.083 \\
120 & 1.098 \\
150 & 1.092 \\
180 & 1.087 \\
210 & 1.092 \\
240 & 1.088 \\
Average & 1.092 \\
Standard Deviation & 0.007 \\
\hline
\end{tabular}

Based on both frequency scanning and on the fact that the most relevant events for cure monitoring occur in a time $t>0$, the work frequency for the dielectric analysis was set on $1.1 \mathrm{kHz}$.

\subsection{DEA}

The DEA was performed using the previously determined frequency of $1.1 \mathrm{kHz}$, in an epoxy resin embedded sensor subjected to an air circulating oven isothermal cure process, at $80^{\circ} \mathrm{C}$, during $240 \mathrm{~min}$. The frequency value and the measurement assembly are in accordance with previous studies on dielectric characterization of polymer and composites ${ }^{3,19,20}$.

Impedance measurements were performed and their results were applied for obtaining the dielectric loss factor ( $\varepsilon$ ") and dielectric constant ( $\left.\varepsilon^{\prime}\right)$ of the material, based on Equations 5 and 6. These properties are presented in Figure 9 (a) and (b) as a function of isothermal curing time.
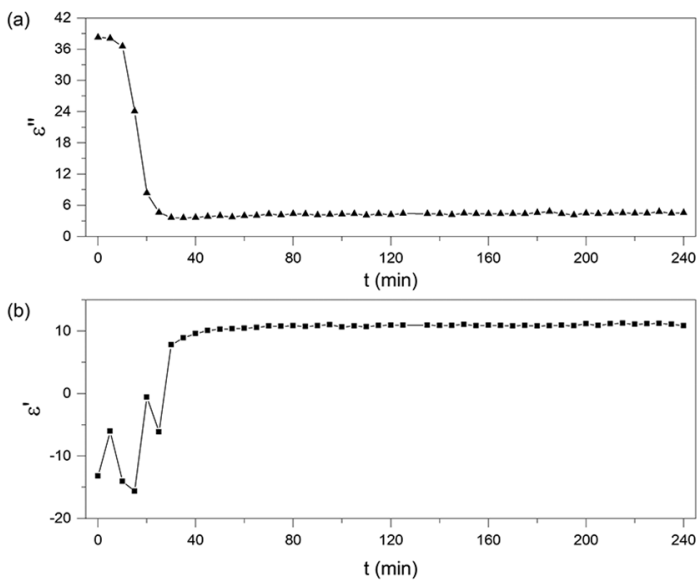

Figure 9. (a) Dielectric loss factor $\varepsilon^{\prime \prime}$ and (b) dielectric constant $\varepsilon^{\prime}$ of the Araldite ${ }^{\mathbb{B}}$ LY5052/Aradur5052 ${ }^{\mathrm{TM}}$ epoxy system under isothermal cure at $80^{\circ} \mathrm{C}$.

It can be noticed that during initial stages of cure, the material presents high values for the dielectric loss factor $\left(\varepsilon\right.$ ") and negative values for the dielectric constant $\left(\varepsilon^{\prime}\right)$. This behavior is explained by the fact that the epoxy resin system presents ions and dipoles that induce conductive and capacitive characteristics ${ }^{12}$. When an electric field is applied in the liquid epoxy system, these ions and dipoles, previously randomly orientated, begin to align themselves regarding the mobility given by the low viscosity ${ }^{21}$.

As the curing process continues to take place, the number of dipolar groups in the reactants decreases ${ }^{22}$ and the increasing viscosity of the reacting system hinders the mobility of ions and dipoles, causing a decrease in $\varepsilon$ " for its direct relationship with the amount of energy dissipated in molecular mobility ${ }^{12}$. The $\varepsilon^{\prime}$ values, on the other hand, go from negative (more conductive behavior) to positive (more dielectric behavior), reaching a constant maximum value of approximately 10. Even though literature usually presents values of 3.0-4.5 for the dielectric constant of cured 
epoxies, these values are often measured at room temperature and dramatically influenced by the applied frequency and environmental conditions ${ }^{23}$. Higher temperatures allow faster movement of the polymer chains and faster alignment of the dipoles, raising the dielectric constant of polymers ${ }^{24}$.

Figure 10 presents the ion viscosity (conductivity) behavior, by confronting its logarithmic results $(\log (I V))$ with the degree of cure obtained by DSC. It can be noticed that the results from both techniques show good correspondence: in approximately $10 \mathrm{~min}$ ( $35 \%$ of cure) the ion viscosity has a rapid increase until $30 \mathrm{~min}(85 \%)$. This behavior is associated with the gelation process and the crosslinking beginning. The resin goes from a liquid with low viscosity, where the ionic impurities in the resin can move freely, to a more viscous system that restricts the ionic diffusion ${ }^{25}$. The possibility of identifying the cure degree of approximately $30 \%$ is especially interesting for the manufacture of pre-impregnated fabrics, in which the thermosetting matrix is usually employed in its B-stage of cure (between 25 to $35 \%$ of curing degree) ${ }^{26}$. As the resin solidifies and the crosslinking starts its completion (95\% of cure) the ion viscosity assumes an approximately constant behavior due to the solid state diffusional regime that predominates the later stages of cure. When the ion viscosity remains constant, the resin is cured ${ }^{25}$.

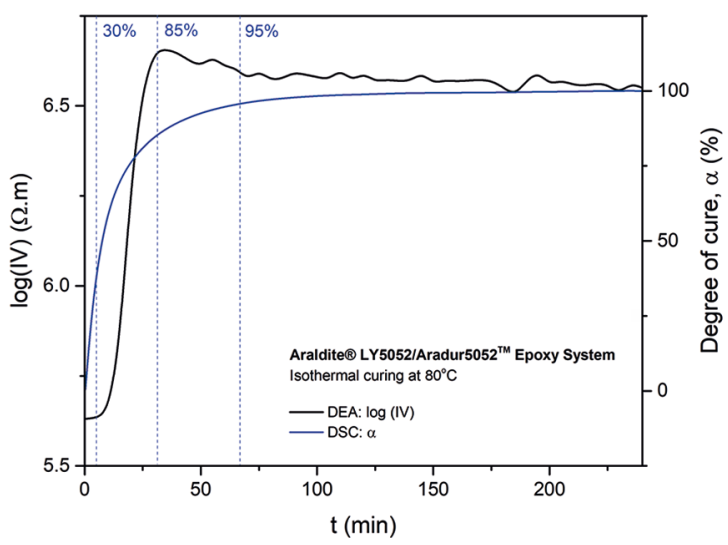

Figure 10. Logarithm of ion viscosity $(\log (\mathrm{IV}))$ versus degree of cure $(\alpha)$ for the Araldite ${ }^{\circledR}$ LY5052/Aradur5052 ${ }^{\mathrm{TM}}$ epoxy system under isothermal cure at $80^{\circ} \mathrm{C}$.

Based on the results obtained by DEA, it is possible to verify the high applicability of the developed module. Its measurements offered reliable data, allowing the calculation of important dielectric properties of the resin as well as the identification of the main transitions that occur during thermosets curing chemical reactions. By presenting a strong correlation with the degree of cure obtained by DSC characterization, the dielectric module has shown itself as an interesting alternative for improving the curing cycle in manufacturing processes of thermoset parts.

\section{Conclusions}

The dielectric module developed in this study presented good potential for the online cure monitoring of epoxy resins in industrial environments. It also provides the opportunity to optimize the curing cycles based on accurate measurements of dielectric properties that can be correlated to the curing stages of thermosets.

These assumptions are made based on the following findings of the study:

- The module has functioned properly by providing an alternate tension to the resin embedded sensor and by being able to correctly measure its impedance response;

- The frequency of $1.1 \mathrm{kHz}$ was found to be the most sensitive for the dielectric measurements;

- The obtained impedance values were successfully used to determine other dielectric properties of the epoxy resin, such as its dielectric constant, loss factor and conductivity, hereby named ion viscosity;

- Good correlation has been demonstrated between the dielectric module results and the well-established thermal analysis technique of DSC, allowing the identification of important transitions in the curing process, like vitrification, gelation and full cure.

Therefore, the low complexity of the dielectric module presented combined with the accuracy of the obtained results, can turn it into a promising and low-cost alternative for performing cure degree measurements in the manufacturing process of composite parts involving epoxy and other thermoset resins. In further works, the authors expect to improve the interdigital sensors sizing and quality and extend the module application to other thermoset resins and pre-impregnated fabrics.

\section{Acknowledgement}

CNPq (Conselho Nacional de Desenvolvimento Científico e Tecnológico), FAPEMIG (Fundação de Amparo à Pesquisa de Minas Gerais) and FINEP (Financiadora de Estudos e Projetos) for their financial support linked to the project number 0.1.13.0169.00.

\section{References}

1. Choi JH, Kim IY, Lee DG. Development of the simple dielectric sensor for the cure monitoring of the high temperature composites. Journal of Materials Processing Technology. 2003;132(13):168-176.

2. Schubel PJ, Crossley RJ, Boateng EKG, Hutchinson JR. Review of structural health and cure monitoring techniques for large wind turbine blades. Renewable Energy. 2013;51:113-123.

3. Kim JS, Lee DG. Online cure monitoring and viscosity measurement of carbon fiber epoxy composite materials. Journal of Materials Processing Technology. 1993;37(1-4):405-416. 
4. Fernando GF, Degamber B. Process monitoring of fibre reinforced composites using optical fibre sensors. International Materials Reviews. 2006;51(2):65-106.

5. Jang BZ, Shin WK. Techniques for cure monitoring of thermoset resins and composites - a review. Materials and Manufacturing Processes. 1990;5(2):301-331.

6. Lionetto F, Maffezzoli A. Monitoring the Cure State of Thermosetting Resins by Ultrasound. Materials. 2013;6(9):37833804 .

7. Antonucci V, Giordano M, Cusano A, Nasser J, Nicolais L. Real time monitoring of cure and gelification of a thermoset matrix. Composites Science and Technology. 2006;66(16):3273-3280.

8. Huntsman. Araldite ${ }^{\circledR}$ LY 5052/Aradur ${ }^{\circledR}$ 5052. [Online]; 2010. Available from: $<$ http://www.swiss-composite.ch/pdf/t-AralditeLY5052-Aradur5052-e.pdf $>$. Access in: 19/7/2016

9. Costa ML, Rezende MC, Pardini LC. Métodos de estudo da cinética de cura de resinas epóxi. Polimeros. 1999;9(2):37-44.

10. ASTM International. ASTM E2041-13e1 - Standard Test Method for Estimating Kinetic Parameters by Differential Scanning Calorimeter Using the Borchardt and Daniels Method. West Conshohocken: ASTM International; 2013.

11. Costa ML, Rezende MC, Botelho EC. Estabelecimento do ciclo de cura de pré-impregnados aeronáuticos. Polímeros. 2005; 15(3):224-231.

12. Hardis R. Cure kinetics characterization and monitoring of an epoxy resin for thick composite structures. [Thesis]. Ames: Iowa State University; 2012.

13. Lee HL. The Handbook of Dielectric Analysis and Cure Monitoring. Cambridge: Lambient Technologies; 2014.

14. Costa ML, Rezende MC, Paiva JMF, Botelho EC. Structural Carbon/Epoxy Prepregs Properties Comparison by Thermal and Rheological Analyses. Polymer-Plastics Technology and Engineering. 2006;45(10):1143-1153.

15. Costa ML, Paiva JMF, Botelho EC, Rezende MC. Avaliação térmica e reológica do ciclo de cura do pré-impregnado de carbono/epóxi. Polímeros. 2003;13(3):188-197.
16. Cheng J, Li J, Zhang JY. Curing behavior and thermal properties of trifunctional epoxy resin cured by 4,4'-diaminodiphenyl sulfone. Express Polymer Letters. 2009;3(8):501-509.

17. Kroutilová I, Matejka L, Sikora A, Soucek K, Stas L. Curing of epoxy systems at sub-glass transition temperature. Journal of Applied Polymer Science. 2006;99(6):3669-3676.

18. Pascault JP, Sautereau H, Verdu J, Williams RJJ. Thermosetting Polymers. New York: Marcel Dekker; 2002.

19. Kim HG, Lee DG. Dielectric cure monitoring for glass/polyester prepreg composites. Composite Structures. 2002;57(1-4):91-99.

20. McIlhagger A, Brown D, Hill B. The development of a dielectric system for the on-line cure monitoring of the resin transfer moulding process. Composites Part A: Applied Science and Manufacturing. 2000;31(12):1373-1381.

21. Mamishev AV, Sundara-Ranjan K, Yang F, Du Y, Zahn M. Interdigital sensors and transducers. Proceedings of the IEEE. 2004;92(5):808-845.

22. Zong L, Kempel LC, Hawley MC. Dielectric studies of three epoxy resin systems during microwave cure. Polymer. 2005;46(8):2638-2645.

23. Johari GP, McAnanama JG, Wasylyshyn DA. The effects of pressure and temperature on molecular dynamics during linearchain polymerization by dielectric measurements. The Journal of Chemical Physics. 1996;105(23):10621-10631.

24. Zeus Industrial Products. Dielectric Properties of Polymers. [Online]; 2005. Available from: $<$ http://www.appstate. edu/ clementsjs/journalarticles/zeus_dielectric.pdf $>$. Access in: $31 / 5 / 2017$.

25. Moghaddam MK, Breede A, Chaloupka A, Bödecker A, Habben C, Meyer EM, et al. Design, fabrication ad embedding of microscale interdigital sensors for real-time cure monitoring during composite manufacturing. Sensors and Actuators A: Physical. 2016;243:123-133.

26. Pardini LC, Peres RJC. Tecnologia de Fabricação de PréImpregnados para Compósitos Estruturais Utilizados na Indústria Aeronáutica. Polímeros. 1996;6(2):32-42. 